\title{
Utilization of Social Media Platform Instagram as Participatory Design Tools in Indonesia
}

\author{
Fitorio Bowo Leksono ${ }^{1}$, Toufiq Panji Wisesa ${ }^{2}$ \\ Product Design, Faculty of Technology and Design, Universitas Pembangunan Jaya, INDONESIA \\ Authors' E-mail: '1 fitorio.leksono@upj.ac.id; ${ }^{2}$ panji.wisesa@upj.ac.id
}

Published: 28 September 2020

\begin{abstract}
Indonesia as the biggest archipelago country in the world has problem for the implementation of participatory design, especially due to the poor communication infrastructure and the distance between host and users. On the other hand, Indonesia has more than 100 million of internet users. In addition, Indonesian also social media savvy with Facebook, Instagram and Twitter serve as the top 3 social media platform in Indonesia. This study explores the potential of Instagram to serve as Participatory Design tools through experimentation method. The outcome of this study is conclusion that will serve as guideline for any Participatory Design initiative in the future.
\end{abstract}

Keywords: Instagram, Participatory Design, Indonesia

eISSN: 2550-214X (0) 2020. The Authors. Published for Idealogy Journal by UiTM Press. This is an Open Access article distributed under the terms of the Creative Commons Attribution-NonCommercial-NoDerivatives License (http://creativecommons.org/licenses/by-nc-nd/4.0/), which permits non-commercial re-use, distribution, and reproduction in any medium, provided the original work is properly cited, and is not altered, transformed, or built upon in any way.

\section{INTRODUCTION}

Participatory Design (PD) is a design methodology in which the future users of a design participate as co-designers in the design process (Christina, 2014). It is often used by experienced designers who recognize difficulties in correctly understanding cultural, social, or usage scenarios faced by their users. C. K. Prahalad and Venkat Ramaswamy received appreciation for bringing joint creations / designs together to the minds of people in the business community by publishing their 2004 book, The Future of Competition: Co-Creating Unique Value with Customers. They propose:

"The meaning of value and the value creation process is rapidly shifting from products and company views to personalized consumer experiences. Consumers who are informed, networked, empowered and actively increasingly create value with the company."

Dominik Mahr, Annouk Lievens, and Vera Blazevic through their research argue that the buyer or user is the focal point of a design process, so understanding their needs and listening to their opinions will lead to successful design results (Mahr, Lievens, and Blazevic, 2013). This is in line with the Human Centered Design trend that is being widely echoed in the professional design and scientific world lately.

Whereas Cecilia Oyugi, Jose Nocera, Lynne Dunckley, and Susan Dray concluded in their research that the implementation of Participatory Design in third world countries experienced problems mainly due to poor communication infrastructure, low interest in reading, distribution of distant dwellings, and the distance between hosts and users (Oyugi, Nocera and Dray, 2008).

Indonesia, as one of third world countries has a problem with communication infrastructure and the distance between host and users. However, Indonesia also one of the countries with significant numbers of internet users, with around 119 million users [4]. In addition, Indonesian also quite social media savvy with Facebook, Instagram and Twitter as the top 3 platform that being use by Indonesian according to Statista (Statista Research Department. 2019). This could compliment the problem of communication in the context of participatory design. 
This study aims to investigate the possibility of social media platform Instagram as a tool for participatory design in Indonesia. The study will contribute to the literature of participatory design in Indonesia.

\section{METHOD}

Experimental method was identified as the most suitable method for this particular research because it provides a high level of control in order to find accurate results that specific and validated (Srinagesh, 2005). This could be beneficial for Indonesian demographic where design is still unpopular.

The experiment in Instagram was conducted in author's personal account with the address (@fitorio) with 1266 followers, through Instagram Stories feature. Most of the followers are Indonesian while the rest are foreign citizens. The experiment was conducted from March 6th - March 18th 2020.

\section{RESULT \& DISCUSSION}

Indonesian is a social media savvy, with Facebook and Instagram as the top 2 social media platform in Indonesia. However, Instagram overcome Facebook in term of user's engagement. A social media engagement study report that Facebook has $0,09 \%$ engagement rate while Instagram has 1,6\% of engagement rate (Rival IQ, 2019). Therefore, considering the importance of participation in a participatory design, Instagram has chosen as the platform for this research.

Just like other social media platform, Instagram also has several features in order to attract users. One of its features is Instagram Stories. Instagram Stories is a feature where user can post related images and/or video content in a slideshow format.

In order to gain an objective result, the experiment was conducted in 4 attempts with various design works, from product, graphic, until service. This experiment will cover tangible and intangible design works. First attempt was designing stool that being shared in Instagram Stories with Polling feature. The respondents were asked to choose the amount of the legs, the material of the legs, then the detail of the legs, and finally the color application. In this experiment, the limitation was the time limit for each step for only 30 minutes. Therefore, the number of participants for this first experiment wasn't that many and from various professional background. In average, there were 34 participants per polling.

The lesson from this experiment is:

(1) The enthusiasm and level of participation for participatory design quite high, probably due to the polling feature that quite easy.

(2) The time limit was too tight that could affect the objectivity of the polling. 

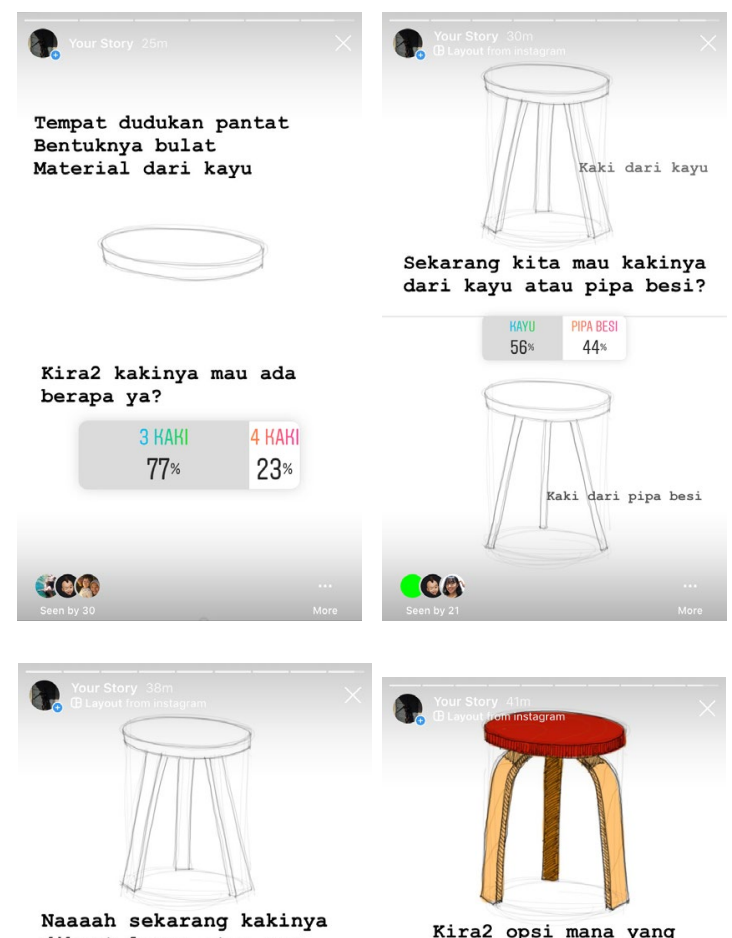

Naaaah sekarang kakiny dilengkungin?
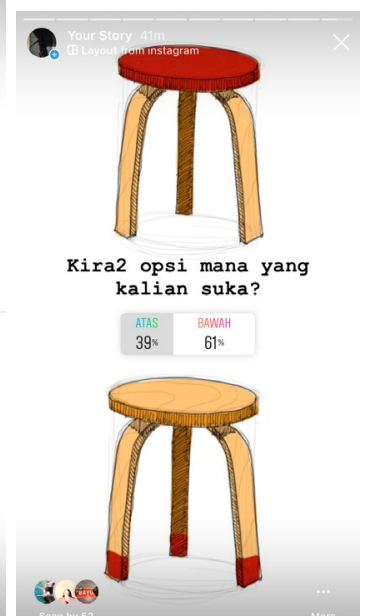

Figure 1: The experiment for stool design session. (Sources: Author)

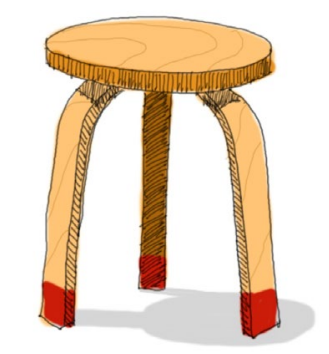

Figure 2: The final result for Stool Session. (Source: Author)

Based on the evidences from first experiment, the second experiment was conducted with longer time frame, which is range from 1-3 hours. The object chosen was still a 3D object because the data that wants to be extracted was the interest of the respondents with the relation of the time limit. Therefore, the object was still same with the previous experiment in order to get the same benchmark.

The number of respondents that participate in the second experiment increased exponentially. In average there were 82 respondents per polling. This experiment show that the length of the time has direct correlation with the number of participants, which indirectly will increase the objectivity of the polling. 

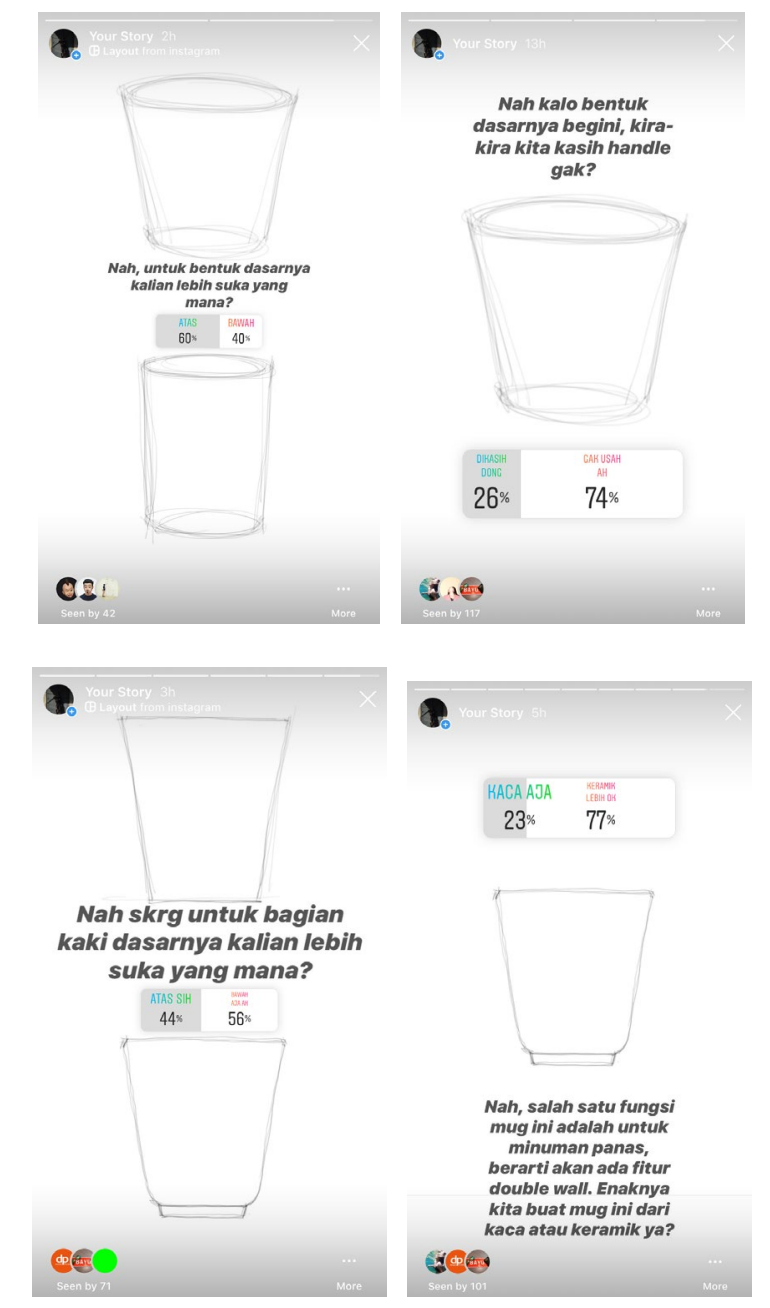

Figure 3: The experiment for Drinkware Session. (Source: Author)

After two experiments with 3D product, the third experiment was conducted with 2D design in the form of logo design. This outcome was to testing if 2D design could get tested with similar method. In addition, in previous experiments, the tool that being used was only Polling, which quite convenience for the participants. In the 3rd experiment, the author adding the feature of Question in order to testing whether the participants would participate if the interaction is more than just a tap but answering the question.

The brief for this experiment was designing a logo for an organic fruit shop called MURNI. Therefore, the design should be able to communicate the business concept. The number of participants for this experiment were slightly increased comparing with previous experiment. In average there were 104 participant per polling, with the exception for Question tool when participant should write their answer, the number of participants decreased significantly, there were only 12 people who participated in the Question. This shows that the participants prefer an easier experience such as polling instead of question. 

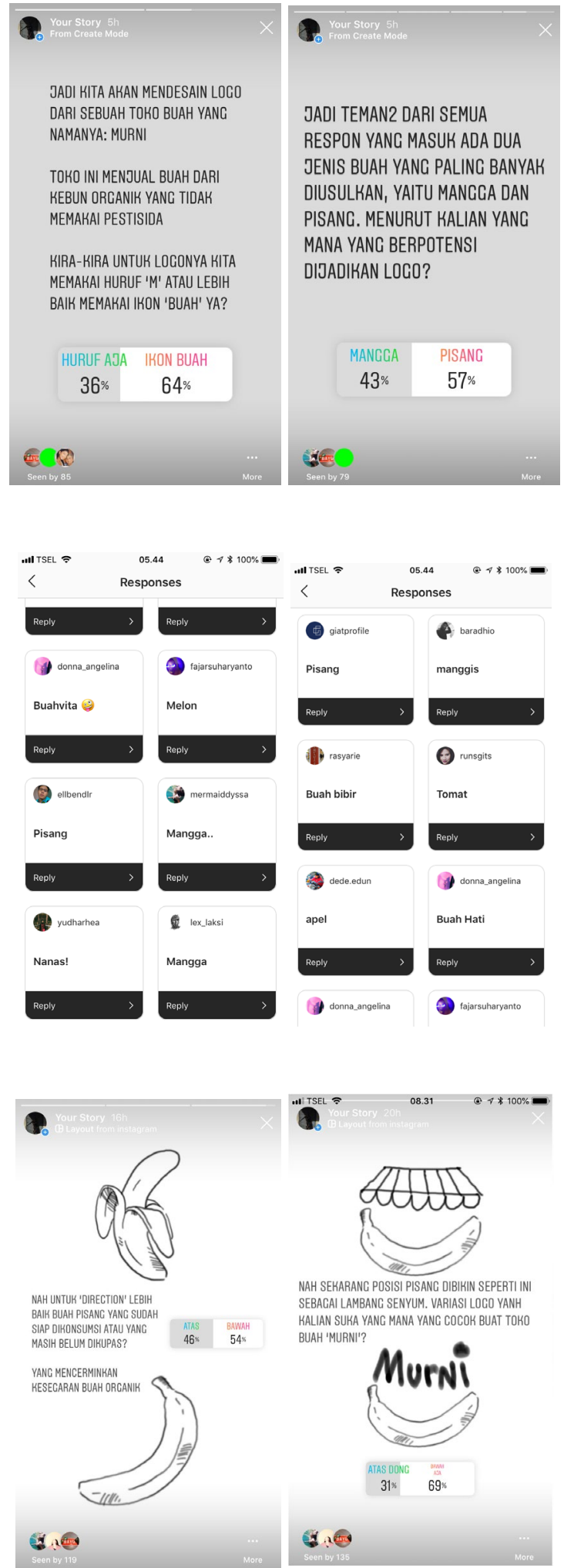

Figure 4: The experiment for Logo Design Session. (Source: Author) 


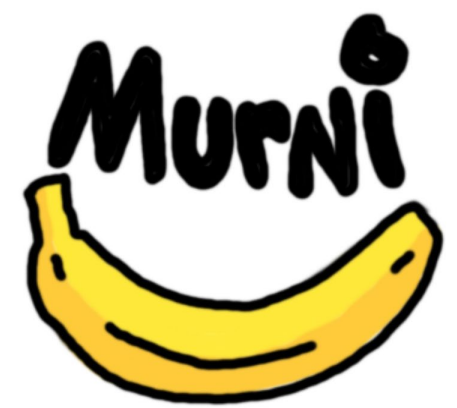

Figure 5: The final result for Logo Design Session. (Source: Author)

The last experiment would be done with intangible design project, in particular a service design. This experiment was quite challenging due to the object was different from all previous experiments where the object was tangible, which mean participants could see the visual of it. The object of the experiment is the service of Gojek, the first Indonesian unicorn. The participants were asked to mention one of their favourite Gojek's services. Since the object of discussion was an intangible object, therefore there was no visual elements that being used. The participants were forced to engage in discussion.

The number of participants during the last experiment was decreased significantly. The average of participants for every question was 10 people. This result was similar with the last session of the previous experiment.

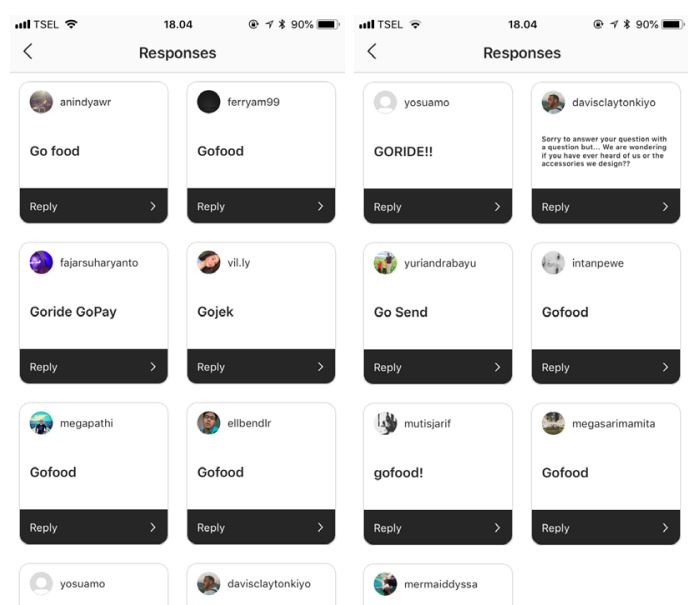

Figure 6: The experiment for service design session (Source: Author) 


\section{CONCLUSION}

Instagram, as one of the most popular social media platforms in Indonesia has a potential to serve as the tool for participatory design through its Instagram Stories feature. This platform could help to gather participants from all over the archipelago with minimal cost. However, this method has some limitations.

1. The questions should be in the form of multiple choices; this will make participants easy to choose option A or option B.

2. The option should have visual element in order to help participants to choose.

3. The timing should be chosen based on the user behaviour of Instagram. Usually it was during lunch time or after office hour.

4. The time limit for every question should be 24 hours in order to gain maximum participants.

5. The project should be a tangible design, as proven from the last experiment about service design. An intangible project would make the participants more difficult to participate.

\section{REFERENCES}

Mahr, Dominik and Lievens, Annouk and Blazevic, Vera, The Value of Customer Co-Created Knowledge during the Innovation Process (March 24, 2013). Journal of Product Innovation Management, Forthcoming. Available at SSRN: https://ssrn.com/abstract=2238605

Mortberg, Christina (2014). "Participatory Design and Design for Value". Linnaeus University. DOI: 10.1007/978-94-007-6994-6 33-1

Oyugi, Cecilia and Nocera, Jose and Dray, Susan, The Challenges for Participatory Design in The Developing World (2008). Proceedings of the Tenth Conference on Participatory Design PDC 2008. DOI: $10.1145 / 1795234.1795308$

Rival IQ. 2019. Social Media Industry Benchmark Report. Retrieved from: https://www.rivaliq.com/blog/2019-social-media-benchmark-report/

Srinagesh, K. The Principles of Experimental Research. Butterworth-Heinemann. 1st December 2005.

Statista Research Department. 2019. Numbers of Internet User in Indonesia from 2017-2023. Retrieved from: https://www.statista.com/statistics/254456/number-of-internet-users-in-indonesia/

Statista Research Department. 2019. Penetration of Leading Social Networks in Indonesia as of 3rd Quarters 2019. Retrieved from: https://www.statista.com/statistics/284437/indonesia-socialnetwork-penetration/ 
Idealogy Journal

Volume 5 Issue 22020

溇 IDEALOGY

JOURNAL 